Article

\title{
Public Assessment of Releasing a Captive Indo-Pacific Bottlenose Dolphin into the Wild in South Korea
}

\author{
Hyo-Jin Kim, Se-Jun Jin and Seung-Hoon Yoo *(1) \\ Department of Energy Policy, Graduate School of Energy \& Environment, Seoul National University of Science \\ \& Technology, 232 Gongreung-Ro, Nowon-Gu, Seoul 01811, Korea; hjinkim@seoultech.ac.kr (H.-J.K.); \\ sjjin@seoultech.ac.kr (S.-J.J.) \\ * Correspondence: shyoo@seoultech.ac.kr; Tel.: +82-2-970-6802
}

Received: 18 May 2018; Accepted: 28 August 2018; Published: 7 September 2018

\begin{abstract}
A captive Indo-Pacific bottlenose dolphin named "Jedol" was released from a zoo into the wild, in Jeju Island Sea off South Korea, in July 2013 to improve his welfare. Since he was illegally captured off the coast of Juju Island in May 2009, he had been performing in dolphin shows at Seoul Zoo, which is owned and operated by the Seoul Metropolitan Government. The release demanded considerable public expenditure, of which the source was local taxes gathered from the residents of Seoul. This paper seeks to conduct an ex-post evaluation of the release, employing the contingent valuation (CV) technique. A total of 500 households living in Seoul in 2013 participated in the CV survey to report their willingness to pay (WTP) for the release. Fifty-two percent were willing to accept an increase in local taxes over the next five years to carry out the release. The mean household WTP estimate was obtained as KRW 4880 (USD 4.56) per annum. The present values of the total WTP and the cost of the release are KRW 79.82 billion (USD 74.53 million) and KRW 751 million (USD 701,000), respectively, in 2013. Interestingly, the former is much more than the latter. We can conclude that the release was desirable from the point of view of Seoul residents.
\end{abstract}

Keywords: animal welfare; contingent valuation; dolphin; public assessment; wild sea; willingness to pay

\section{Introduction}

A four-year investigation conducted by the National Fisheries Research and Development Institute (NFRDI) in Korea (2007-2010) on common bottlenose dolphins along the coast of Jeju identified these dolphins to be Indo-Pacific bottlenose dolphins (Tursiops aduncus), distinct from the common bottlenose dolphins (Tursiops truncatus) inhabiting the waters of the eastern and southern Korean coastline. Indo-Pacific bottlenose dolphins, with a longer beak and more slender body shape than common bottlenose dolphins, measure a maximum length and weight of $2.7 \mathrm{~m}$ and $230 \mathrm{~kg}$, respectively [1].

Along coastal areas, Indo-Pacific bottlenose dolphins are exposed to a wide variety of threats in addition to direct and indirect captures. Threats that are cause for concern include: (1) the toxic effects of xenobiotic chemicals; (2) reduced prey availability caused by environmental degradation and overfishing; (3) direct and indirect disturbance and harassment (e.g., boat traffic and commercial dolphin watching and interactive programs); (4) marine construction and demolition; and (5) other forms of habitat destruction and degradation (including anthropogenic noise). Eventually, the Korean Ministry of Oceans and Fisheries adopted the stance that returning the surviving Indo-Pacific bottlenose dolphins to their home range is essential for the survival of the stock [2]. Monitoring by NFRDI indicated that Indo-Pacific bottlenose dolphins had increased along the Jeju coastline between 2012 and 2017, despite numbers dropping from 2008 to 2012, with an estimated 22 dolphins caught in nets 
from 2008 to 2010 [3]. Latest survey records (2017) indicated 117 Indo-pacific dolphins along the coast of Jeju island [4].

The Korean Ministry of Oceans and Fisheries revised the Regulations of Marine Ecosystem Conservation and Management in June 2012 to reclaim Indo-Pacific bottlenose dolphins and designate them as an endangered marine species. Subsequently, seven dolphins, which had been illegally captured, were released between 2013 and 2017 into the wild. Today, populations of dolphins are beginning to gradually recover. Local Jeju fishermen are voluntarily participating in the government's active countermeasures. For instance, dolphins that are caught accidentally during fishing operations are no longer illegally captured but instead released immediately on site by the fishermen.

An Indo-Pacific bottlenose dolphin was caught in a fishing net off the coast of Jeju Island in May 2009 and then illegally traded. At the city-run Seoul Zoo, where he was named Jedol, he was used in dolphin shows until July 2011, when news of his illegal capture drew public complaints. Thus, Seoul Zoo stopped the dolphin show and ran an ecological demonstration aimed at educating people about the conservation value of dolphins. The dolphins, including Jedol, were well protected by zookeepers at Seoul Zoo. However, on 12 March 2012, Seoul Metropolitan police and Seoul Zoo announced a plan that one of the captive dolphins would be released back into the wild. The announcement has led to fundamental concerns about the relationships between animals, nature, and humans.

Seoul Zoo set up a Citizen Committee made up of 14 members including researchers, university professors, and non-governmental organization groups prior to releasing Jedol. The committee decided to reintroduce Jedol to the sea, designing a soft release protocol. Seoul Metropolitan government, which established and operates Seoul Zoo, also agreed with the protocol, mainly as it would improve Jedol's wellbeing. Finally, Jedol was released into the sea near Kimnyoung on Jeju Island on 18 July 2013 from an offshore pen where they had been training him to adapt to the wild for more than a year. The release demanded considerable public expenditure, which is derived from local taxes collected from the residents of Seoul. Thus, public assessment of the release is required. Moreover, whether the economic benefits of the release were more than the costs of the release should be examined to ascertain whether the release was socially profitable.

As far as the authors are aware, there have been no studies dealing with the public value of dolphins or releasing wild animals. However, many studies evaluate the public value of protecting endangered species in the literature. For example, Giraud et al. [5] reported that the average of the conservation benefit of the Steller sea lion (Eumetopias jubatus) in the United States was USD 61.13 per household per year. The economic value of Steller sea lions was a maximum of USD 204 per household per year [6]. The mean willingness of U.S. households to pay for improving only the status of the Hawaiian monk seal (Monachus schauinslandi) from endangered to recovered was USD 68.12 per year [7]. Boxall et al. [8] estimated the economic values of marine mammal species, such as beluga whales (Delphinapterus leucas), harbor seals (Phoca vitulina), and blue whales (Balaenoptera musculus) found in the St. Lawrence Estuary in Canada, and found that they ranged from USD 77 to 229 per household per year. A study by Stithou and Scarpa [9] in Greece put values of EUR 12.40 and EUR 12.04 on turtle and seal conservation as a visitor's landing fee, respectively. Kontogianni et al. [10] used the CV method and discovered that people in Greece could pay an additional EUR 87.1 with their water bill in order to conserve the Mediterranean monk seal (Monachus monachus). Kim et al. [11] applied a CV method to find that South Koreans were willing to pay a monetary amount to protect the spotted seal (Phoca largha) located in the area of Baengnyeong Island. Bosetti and Pearce [12] carried out a CV survey to estimate willingness to pay (WTP) for recreational use of seals and found that the mean WTP estimates for seeing seals recovered from an accident in a specialized sanctuary and seeing seals in the wild are GBP 8 and 9 per person, respectively. The mean annual WTP values for recovering humpback whales (Megaptera novaeangliae) and southern resident killer whales (Orcinus orca) in the United States were estimated at USD 60.98 and 84.38 per household per year, respectively [13]. 
This study seeks to conduct an ex-post evaluation of the release employing contingent valuation (CV) approach and an ex-post cost-benefit analysis of the release. A total of 500 households living in Seoul participated in the CV survey to ask their WTP for the release in the case that the release had not been implemented. As far as we are aware, this is the first study to evaluate the public value of releasing a captive dolphin to the wild.

\section{Methodology}

\subsection{Method: $C V$}

Animal welfare is an important research topic in the literature [14,15]. The prime purpose of the release was to improve Jedol's welfare and protect the ecosystem. This paper tries to assess the public value of the lease. A technique that has been frequently used in the literature is the CV approach $[5,6,8,16-20]$. This is because it is known to effectively capture the non-use value of endangered species $[5,6,8]$. It is a kind of stated preference method for estimating the non-market economic values of conserving certain environmental goods [16-18]. It is meant to express citizens' interests and establish the value they place on environmental concerns with no formal market, given the type of good in question $[19,20]$. Therefore, this paper employs the CV technique and the public value of the release. The CV technique usually asks randomly selected respondents to state their WTP for conducting the lease. In the microeconomics sense, the WTP represents the public value or the economic benefits of the release [21].

An application of the CV calls for a survey of citizens to be undertaken. Therefore, well-crafted questionnaires and scientific sampling and surveys are key to determining the success of $C V$ applications. In this regard, we followed the guidelines and recommendations presented in Arrow et al. [22] and Johnston et al. [23] in applying CV. This study strove to reflect them in implementing the CV survey and making the $\mathrm{CV}$ survey questionnaire, as will be explained below.

\subsection{Sampling and Survey Questionnaire}

Seoul Metropolitan Government was the main driver of the release of Jedol and the local tax paid by Seoul citizens was the source of funds for the expense of releasing Jedol. Thus, the spatial scope of the study is Seoul, South Korea. There were 3,567,727 households in Seoul in 2013 [24]. We selected the sample size within our budget constraints according to the adequate statistical criterion and divided Seoul into 25 zones to extract 500 random samples from Seoul. Based on the census data, each zone was assigned a number of respondents and random sampling was conducted within each zone. For the zones surveyed, which included Jongno, Jung, Yongsan, Seongdong, Gwangjin, Dongdaemun, Jungnang, Seongbuk, Gangbuk, Dobong, Nowon, Eunpyeong, Seodaemun, Mapo, Yangcheon, Gangseo, Guro, Geumcheon, Yeongdeungpo, Dongjak, Gwanak, Seocho, Gangnam, Songpa, and Gangdong, the sample sizes were $8,7,12,15,19,18,21,23,17,17,28,22,16,20,22,28$, 20, $12,20,21,31,20,29,31$, and 23 , respectively.

A pre-assessment using the 30 interviewees, who were sampled from randomly chosen households over the entire Seoul, was undertaken to examine whether an initial version of the questionnaire had some errors or unclearness. The results of this in-depth pilot interview were used to refine the questionnaire for its use in actual field survey. The final questionnaire comprised four sections: first, the background and purpose of the survey; second, questions that lead to the opinions and judgments of the interviewer about freeing Jedol and returning him to the wild; third, questions related to the WTP for the release; fourth, questions about respondents' socioeconomic properties.

\subsection{WTP Elicitation}

In CV application studies, questions should be effectively asked to ensure that the WTP of the respondents is well elicited. In recent CV studies, open-ended question such as "How much will you pay for the release?" is not very good. Instead, closed-ended question asking "Are you willing to pay a 
certain amount for the release?" should be used. This is because the latter is similar to the way people decide whether they buy a good or not in the market and thus incentive-compatible and familiar. In this paper, a closed-ended question is applied following Arrow et al.'s [22] recommendation of its use.

In applying the closed-ended question, a payment vehicle should be offered to people so that they do not have any difficulty in responding to the question. The payment vehicle can be said to be a medium that identifies the WTP. Usually, a tax has been most widely used in South Korea. This is because the use of tax as a payment vehicle can reduce the likelihood that people will overstate the WTP and people are familiar with the payment vehicle of a tax. Therefore, in this paper, local tax is used as the payment vehicle. More specifically, property tax, one of the local taxes, is used as a payment vehicle since the revenue from property tax covers the cost required to release Jedol.

The WTP question was posed in the following manner: "Would your household be willing to pay a certain amount for releasing Jedol to the wild through an increase in local tax, supposing that the release will certainly be implemented?" Moreover, some additional statements concerning payment were provided in the survey questionnaire. For example, the respondents were told: "If a majority of respondents refuse to pay the cost, the release cannot be implemented. However, if a majority of respondents accept the payment, the release can be implemented. Please keep in mind that your household's income is constrained and that there are various expenditures in your household."

\subsection{Model of WTP}

We used an economic and statistical model of the closed-ended WTP data, known as the utility difference approach [25]. In the closed-ended question CV survey, the $t$-th interviewee is faced with a question of whether she/he is willing to pay an amount, $D_{t}$, for the release. If her/his WTP, $W_{t}$, is more than or equal to $D_{t}\left(W_{t} \geq D_{t}\right)$, she/he will answer "yes". If her/his WTP is less than $D_{t}\left(W_{t}<D_{t}\right)$, her/his response is "no." To specify the responses, an indicator variable, $E_{t}^{Y E S}$, can be introduced such that the value is one if the response is "yes" and zero otherwise.

Moreover, we consider that a response of "no" implies two cases: positive WTP less than $D_{t}$ $\left(0<W_{t}<D_{t}\right)$ and zero WTP $\left(W_{t}=0\right)$. The first is an interval data and the second is a point data. One more binary variable $E_{t}^{0}$, can be formulated such that the value is zero if the WTP is non-zero and one if the WTP is zero. Thus, there are three cases:

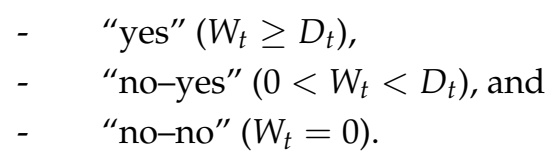

We utilized a spike model to analyze our SB DC CV data with zero observations. The spike model given in Kriström [26] can be usefully employed to deal with the WTP data. Out of the 500 respondents, $242(48.4 \%)$ stated zero WTP values. Usually, the model of WTP is specified as:

$$
G_{W}\left(D ; \delta_{0}, \delta_{1}\right)=\left\{\begin{array}{l}
{\left[1+\exp \left(\delta_{0}-\delta_{1} D\right)\right]^{-1} \text { if } D>0} \\
{\left[1+\exp \left(\delta_{0}\right)\right]^{-1} \text { if } D=0} \\
0 \text { if } D<0
\end{array},\right.
$$

where $G_{W}(\cdot)$ is the WTP distribution function, and $\delta_{0}$ and $\delta_{1}$ are the parameters of $G_{W}(\cdot)$.

When the number of observations is $T$, the log-likelihood function of the model is:

$$
\begin{aligned}
\ln L & =\sum_{t=1}^{T}\left\{E_{t}^{Y E S} \ln \left[1-G_{W}\left(D_{t} ; \delta_{0}, \delta_{1}\right)\right]\right. \\
& +\left(1-E_{t}^{0}\right)\left(1-E_{t}^{Y E S}\right) \ln \left[G_{W}\left(D_{t} ; \delta_{0}, \delta_{1}\right)-G_{W}\left(0 ; \delta_{0}, \delta_{1}\right)\right] \\
& \left.+E_{t}^{0}\left(1-E_{t}^{Y E S}\right) \ln G_{W}\left(0 ; \delta_{0}, \delta_{1}\right)\right\}
\end{aligned}
$$


The estimates for $\delta_{0}$ and $\delta_{1}$ can be derived through the maximum likelihood estimation method. The average WTP is obtained as $\left(1 / \delta_{1}\right) \ln \left[1+\exp \left(\delta_{0}\right)\right]$ [26].

\section{Results}

\subsection{Data}

A survey of 500 Seoul citizens was administered during December 2013. The list of bids $\left(D_{t}\right)$ employed in this paper is KRW 1000, 2000, 3000, 5000, 7000, and 10,000, which were determined from the outcomes of the focus group interview. The interviewees' responses are summarized in Table 1. As addressed above, 242 interviewees reported zero WTP. Two main reasons for why they stated zero WTP are that they do not place a value on the release and they do not have sufficient income to pay something towards the release.

Table 1. Willingness to pay (WTP) responses.

\begin{tabular}{ccccc}
\hline Bid Amount $^{\text {a }}$ & $\begin{array}{c}\text { WTP Is More than the } \\
\text { Bid Amount (\%) }\end{array}$ & $\begin{array}{c}\text { WTP Is More than Zero and Less } \\
\text { than the Bid Amount (\%) }\end{array}$ & WTP Is Zero (\%) & Sample Size $^{\mathbf{b}}$ \\
\hline 1000 & $45(53.6 \%)$ & $4(4.8 \%)$ & $35(41.7 \%)$ & $84(100.0 \%)$ \\
2000 & $38(45.8 \%)$ & $4(4.8 \%)$ & $41(49.4 \%)$ & $83(100.0 \%)$ \\
3000 & $32(38.6 \%)$ & $12(14.5 \%)$ & $39(47.0 \%)$ & $83(100.0 \%)$ \\
5000 & $23(27.4 \%)$ & $13(15.5 \%)$ & $48(57.1 \%)$ & $84(100.0 \%)$ \\
7000 & $24(28.9 \%)$ & $24(28.9 \%)$ & $35(42.2 \%)$ & $83(100.0 \%)$ \\
10,000 & $17(20.5 \%)$ & $22(26.5 \%)$ & $44(53.0 \%)$ & $83(100.0 \%)$ \\
Totals & $179(35.8 \%)$ & $79(15.8 \%)$ & $242(48.4 \%)$ & $500(100.0 \%)$ \\
\hline
\end{tabular}

Note: ${ }^{a}$ The unit is Korean won (USD 1.0 = KRW 1071 at the time of the survey); ${ }^{b}$ The numbers in parentheses next to the number of responses represent the percentage of the sample size.

\subsection{Estimation Results}

Covariates mean the factors that can have an effect on the probability of answering "yes" to a given bid. Usually, the interviewees' characteristics are used as covariates. Usually, the covariates are reflected in the model by inserting them into $\delta_{0}$ in Equation (1). We consider four variables: income, age, education, and gender. The variables are explained in Table 2 . Therefore, a positive sign of the coefficient for a variable implies that the bigger the value of the variable the higher the possibility of responding "yes" to a provided bid.

Table 2. Description of the variables used for covariates.

\begin{tabular}{cccc}
\hline Variables & Definitions & Mean & Standard Deviation \\
\hline Income & The household's monthly income before tax & 4.44 & 2.20 \\
Age & (unit: million Korean won) & 45.73 & 9.06 \\
Education & The respondent's age in years & 14.34 & 2.30 \\
Gender & The respondent's education level in years & 0.50 \\
\hline
\end{tabular}

Estimation results of the model without covariates are reported in Table 3. The coefficient estimate for bid amount is statistically meaningful and negative. The spike, which implies the possibility of reporting zero WTP, is estimated as 0.4847 . This is equivalent to the sample proportion of zero WTP (48.4\%). The average household WTP is KRW 4880 (USD 4.56) per annum and statistically significant, though the constant term is not. Moreover, the table presents the confidence intervals for the mean WTP estimate. The confidence intervals are calculated by the use of the Monte Carlo simulation technique suggested by Krinsky and Robb [27] with 5000 replications. The Wald statistic indicates that the estimated utility function is statistically significant.

Usually, a WTP value for achieving an improvement or avoiding deterioration can be added to the social benefits or costs. The WTP value depends on the respondents' socioeconomic characteristics as 
well as the amount of improvement or deterioration. In other words, the WTP value has the individual heterogeneity in terms of using a survey of respondents and quantifying the social benefits or costs. Thus, the authors try to estimate the model with covariates that imply the respondents' socioeconomic characteristics. The model can reflect the individual heterogeneity. Moreover, the mean WTP estimate obtained from the model with covariates is also reported in the third column of Table 3 in order to consider the individual heterogeneity in computing a representative household's benefits of the release. In the course of estimating the mean WTP, the sample mean values for the covariates are used. If another sample is employed, we can re-estimate the mean WTP using the results shown in Table 3 and the values for the sample's covariates.

Estimation results of the model with covariates are also presented in Table 3. The estimate for bid amount is statistically significant and negative. The coefficient estimates for Income and Age variables are statistically significant, but those for the Education and Gender variables are not. Wealthier interviewees are more inclined to accept the payment of an offered bid than less wealthy interviewees. Similarly, the respondent's age has a negative relation to the likelihood of saying "yes" to a presented bid.

Table 3. Estimation results of the models.

\begin{tabular}{|c|c|c|}
\hline \multirow{2}{*}{ Variables $^{a}$} & \multicolumn{2}{|c|}{ Estimates $^{\mathrm{d}}$} \\
\hline & The Model without Covariates & The Model with Covariates \\
\hline Constant & $0.0612(0.68)$ & $1.4642(1.64)$ \\
\hline Bid amount ${ }^{b}$ & $-0.1484(-9.86){ }^{\#}$ & $-0.1539(-9.91) \#$ \\
\hline Income & & $0.1240(3.04)^{\#}$ \\
\hline Age & & $-0.0314(-3.04)^{\#}$ \\
\hline Education & & $-0.0434(-1.05)$ \\
\hline Gender & & $0.2007(1.14)$ \\
\hline Spike & $0.4847(21.69){ }^{\#}$ & 0.4865 (21.46) \# \\
\hline Average WTP per household per annum & KRW 4880 (USD 4.56) & KRW 4682 (USD 4.37) \\
\hline$t$-value & $9.75^{\#}$ & $9.64^{\#}$ \\
\hline $95 \%$ confidence interval & KRW 4041 to 6061 (USD 3.77 to 5.66) & KRW 3909 to 5827 (USD 3.65 to 5.44 ) \\
\hline $99 \%$ confidence interval & KRW 3783 to 6622 (USD 3.53 to 6.18 ) & KRW 3716 to 6243 (USD 3.47 to 5.83 ) \\
\hline Sample size & 500 & 500 \\
\hline Log-likelihood & -483.98 & -474.30 \\
\hline Wald statistic ( $p$-value $)^{c}$ & $470.56(0.000)$ & $460.37(0.000)$ \\
\hline
\end{tabular}

Notes: ${ }^{\text {a }}$ Table 2 explains the variables; ${ }^{\mathrm{b}}$ The unit is KRW 1000, and the exchange rate was USD $1.0=$ KRW 1071 at the time of the survey; ${ }^{\mathrm{C}}$ It is computed under the null hypothesis of all the parameters' being jointly zero; ${ }^{\mathrm{d}}$ The values reported in parentheses beside the estimates are $t$-values. ${ }^{\#}$ denotes statistical significance at the $1 \%$ level.

\subsection{Discussion of the Results}

There were 3,567,727 households in Seoul in 2013 [27]. As stated above, a professional survey company conducted a random sampling in each zone of Seoul trying to maintain the consistency with the population characteristics. For example, the sample averages of gender, household income, and household size are similar to the population averages reported in Statistics Korea [27]. Hence, the mean WTP estimate for the sample can be utilized to compute the population WTP value. That is, the multiplication of the sample mean by the number of household gives us KRW 17.4 billion (USD 16.3 million) per year.

This value indicates the public value or the economic benefits of the release, which can be compared with the cost of the release. The cost was KRW 0.75 billion (USD 0.70 million) in 2013. Considering that the social discount rate officially used in South Korea is $4.5 \%$, the present values of the total WTP for five years (from 2013 to 2017) and the cost us KRW 79.82 billion (USD 74.53 million) and KRW 751 million (USD 701 thousand), respectively, in 2013. Interestingly, the first is much greater than the second. Consequently, the release passed the test of the cost-benefit analysis. That is, the release was socially desirable and justifiable, and supported by the Seoul citizens. 


\section{Conclusions}

The study sought to evaluate the public value of releasing into the wild an illegally captured Indo-Pacific dolphin, named Jedol, who had been in captivity for over four years, and performing in a dolphin show at Seoul Zoo for much of that time. For this purpose, the CV method was applied to 500 randomly selected residents of Seoul, Korea's capital city, which is home to one-fifth of the country's total population. We discovered that the mean WTP for the release was KRW 4880 won (USD 4.56) per household per year, which was KRW 17.4 billion (USD 16.3 million) per year when expanded to the entire city. This value was statistically significant and much higher than the cost of releasing Jedol. The cost of releasing Jedol was gathered from Seoul residents' local taxes. Therefore, we can conclude that the release was desirable from the perspective of Seoul residents.

As of May 2018, Jedol appears to be quite healthy and fully adapted to his new environment, living in a pod of dolphins near Jeju Island. After the release was realized by Seoul Metropolitan Government, four other dolphins that were illegally captured and sold to a private company for a dolphin show were confiscated by the Supreme Court of South Korea. Unfortunately, two of these did not adapt to the wild after release and had to be transferred to Seoul Zoo. However, using the lessons learned in Jedol's successful release, the other two captive dolphins were successfully released to the wild after training for their rehabilitation at the sea pen off the coast of Jeju Island. Now they are living with Jedol and his pod of dolphins near Jeju Island. An additional benefit of such a release program of captive dolphins is collaboration between the government, citizens, and non-governmental organizations.

Follow-up work needs to be performed in the next phase of this study. This research, limited to the Seoul population, needs to be extended to include the entire country, since releasing animals from any local zoo to the wild draws attention from the media not only from that area but also on a national level. Moreover, the authors think that the framework of the study can be extended in future studies in several ways. First, since the release into the wild of animals other than dolphins is being pushed forward, the public value of releasing other animals into the wild should be assessed and compared with the results of this study. In South Korea, for example, the release of animals such as bears, foxes, and wildcats at zoos is underway. Second, if the results of this paper on the Indo-Pacific bottlenose dolphin are compared with those of other countries, new implications can be found. To our knowledge, there are many cases of estimating the public value of preserving animals in their natural state, but a case study evaluating public assessment of wild release of animals from captivity could not be found in the literature.

Author Contributions: All the authors participated in writing this paper. H.-J.K. formulated the model adopted in this study and wrote most of the paper; S.-J.J. conducted an empirical analysis of collected data and reported the implications of the study; S.-H.Y. made the CV survey instrument and supervised the field survey to collect the data.

Acknowledgments: This study was supported by the Research Program funded by the SeoulTech (Seoul National University of Science and Technology).

Conflicts of Interest: The authors declare no conflict of interest.

\section{References}

1. Kim, H.W.; Choi, S.G.; Kim, Z.G.; An, Y.R.; Moon, D.Y. First record of the Indo-Pacific bottlenose dolphin, Tursiops aduncus, in Korean waters. Anim. Cells Syst. 2010, 14, 213-219. [CrossRef]

2. Kim, S.; Tatar, B. Dolphin liberation in Korea: Is it beneficial for conservation? Coast. Manag. 2018, 46, 222-234. [CrossRef]

3. Press Releases of Ministry of Oceans and Fisheries. Sejong-si, Korea, 2018. Available online: http:/ / www. mof.go.kr (accessed on 2 May 2018).

4. Song, K.J. Status of Indo-Pacific bottlenose dolphins (Tursiops aduncus) around Jeju Island, Korea. Pac. Sci. 2014, 68, 555-562. [CrossRef]

5. Giraud, K.; Turcin, B.; Loomis, J.; Cooper, J. Economic benefit of the protection program for the Steller sea lion. Mar. Policy 2002, 26, 451-458. [CrossRef] 
6. Lew, D.K.; Layton, D.F.; Rowe, R.D. Valuing enhancements to endangered species protection under alternative baseline futures: The case of the steller sea lion. Mar. Resour. Econ. 2010, 25, 133-154. [CrossRef]

7. Wallmo, K.; Lew, D.K. Valuing improvements to threatened and endangered marine species: An application of stated preference choice experiments. J. Environ. Manag. 2011, 92, 1793-1801. [CrossRef] [PubMed]

8. Boxall, P.C.; Adamowicz, W.L.; Olar, M.; West, G.E.; Cantin, G. Analysis of the economic benefits associated with the recovery of threatened marine mammal species in the Canadian St. Lawrence Estuary. Mar. Policy 2012, 36, 189-197. [CrossRef]

9. Stithou, M.; Scarpa, R. Collective versus voluntary payment in contingent valuation for the conservation of marine biodiversity: An exploratory study from Zakynthos, Greece. Ocean Coast. Manag. 2012, 56, 1-9. [CrossRef]

10. Kontogianni, A.; Tourkolias, C.; Machleras, A.; Skourtos, M. Service providing units, existence values and the valuation of endangered species: A methodological test. Ecol. Econ. 2012, 79, 97-104. [CrossRef]

11. Kim, J.Y.; Mjelde, J.W.; Kim, T.K.; Lee, C.K.; Ahn, K.M. Comparing willingness-to-pay between residents and non-residents when correcting hypothetical bias: Case of endangered spotted seal in South Korea. Ecol. Econ. 2012, 78, 123-131. [CrossRef]

12. Bosetti, V.; Pearce, D.W. A study of environmental conflict: The economic value of Grey Seals in southwest England. Biodivers. Conserv. 2003, 12, 2361-2392. [CrossRef]

13. Wallmo, K.; Lew, D.K. A comparison of regional and national values for recovering threatened and endangered marine species in the United States. J. Environ. Manag. 2016, 179, 38-46. [CrossRef] [PubMed]

14. Rose, M.A. Challenges to the development and implementation of public policies to achieve animal welfare outcomes. Animals 2011, 1, 69-82. [CrossRef] [PubMed]

15. Powell, D.M.; Watters, J.V. The evolution of the animal welfare movement in U. S. zoos and aquariums. Der Zoologische Garten 2017, 86, 219-234. [CrossRef]

16. Sanchirico, N.J.; Lew, K.D.; Haynie, C.A.; Kling, M.D.; Layton, F.D. Conservation values in marine ecosystem-based management. Mar. Policy 2013, 38, 523-530. [CrossRef]

17. Naald, V.B.; Cameron, A.T. Willingness to pay for other species' well-being. Ecol. Econ. 2011, 70, $1325-1335$. [CrossRef]

18. Engel, T.M.; Marchini, S.; Pont, C.A.; Machado, R.; Oliveira, R.L. Perceptions and attitudes towards the wildlife refuge of Ilha dos Lobos, a marine protected area in Brazil. Mar. Policy 2014, 45, 45-51. [CrossRef]

19. Kim, J.; Lim, S.Y.; Yoo, S.H. Measuring the economic benefits of designating Baegnyeong Island in Korea as a marine protected area. Int. J. Sustain. Dev. World Ecol. 2017, 24, 205-213. [CrossRef]

20. Lim, S.Y.; Jin, S.J.; Yoo, S.H. The economic benefits of the Dokdo Seals restoration project in Korea: A contingent valuation study. Sustainability 2016, 8, 900. [CrossRef]

21. Brent, R.J. Applied Cost-Benefit Analysis, 2nd ed.; Edward Elagr: Cheltenham, UK, 2006.

22. Johnston, R.J.; Boyle, K.J.; Adamowicz, W.; Bennett, J.; Brouwer, R.; Cameron, T.A.; Hanemann, W.M.; Hanley, N.; Ryan, M.; Scarpa, R.; et al. Contemporary guidance for stated preference studies. J. Assoc. Environ. Resour. Econ. 2017, 4, 319-405. [CrossRef]

23. Arrow, K.; Solow, R.; Portney, P.R.; Leamer, E.E.; Radner, R.; Schuman, H. Report of the NOAA panel on contingent valuation. Fed. Regist. 1993, 58, 4601-4614.

24. Statistics Korea. Available online: http://kosis.kr (accessed on 15 May 2018).

25. Hanemann, W.M. Welfare evaluations in contingent valuation experiments with discrete responses. Am. J. Agric. Econ. 1984, 66, 332-341. [CrossRef]

26. Kriström, B. Spike models in contingent valuation. Am. J. Agric. Econ. 1997, 79, 1013-1023. [CrossRef]

27. Krinsky, I.; Robb, A.L. On approximating the statistical properties of elasticities. Rev. Econ. Stat. 1986, 68, 715-719. [CrossRef]

(C) 2018 by the authors. Licensee MDPI, Basel, Switzerland. This article is an open access article distributed under the terms and conditions of the Creative Commons Attribution (CC BY) license (http:/ / creativecommons.org/licenses/by/4.0/). 